\title{
The Evaluation of the Actual Fracture Energy of the Carbon Fiber Reinforced Silicon Nitride Composite by the Kr-BET Adsorption Technique
}

\author{
Kouichi YASUDA, Shigenari OHSAWA, Yohtaro MATSUO and Shiushichi KIMURA \\ Department of Inorganic Materials, Faculty of Engineering, Tokyo Institute of Technology, 2-12-1, Ookayama, Meguro-ku, Tokyo \\ Kr-BET 吸着法による炭素繊維強化窒化ケイ素複合材料の実破壊エネルギーの評価 \\ 安田公一・大沢栄也・松尾陽太郎・木村脩七 \\ 東京工業大学工学部無機材料工学科, 152 東京都目黒区大岡山 2-12-1
}

152

[Received November 14, 1991; Accepted January 24, 1992]

\begin{abstract}
The fracture surface area of the chevron-notched carbon fiber reinforced silicon nitride composite was measured by the Kr-BET adsorption technique. The energyabsorbing mechanism of the composite was discussed on the basis of the actual fracture energy. The average actual fracture energy of the composite is nearly the same as the fracture energies of polycrystalline ceramics. This fact suggests that the large energy-absorbing capacity of the composite depends on how the fracture surface area can increase. Furthermore, application of the loading/unloading technique reveals that the actual fracture energy of the composite increases to a maximum at an initial stage of the failure, and then decreases to a constant value at a final stage. This indicates that the energy-absorbing mechanism changes from the formation of the fracture surface to the pullout of fibers.
\end{abstract}

Key-words : Fracture energy, Composite, BET adsorption

1. Introduction

Many studies ${ }^{1)-16)}$ have been carried out on the work of fracture to evaluate the fracture energy of ceramic materials. Most of polycrystalline ceramics have the fracture energies from 10 to $100 \mathrm{~J} / \mathrm{m}^{2}$, which are ten times larger than the thermodynamic surface energies. Recently, the work of fracture technique has been applied to fiber reinforced ceramic matrix composites, ${ }^{17)-19)}$ because the main crack of the composites can not be clearly observed, and so ordinary fracture mechanical techniques have not been strictly used to composites. The observed fracture energies of composites are more than $1000 \mathrm{~J} / \mathrm{m}^{2}$.

In previous studies, however, a projection area of a notch-ligament in the specimen was used as the nominal fracture surface area. Therefore, the discussions about the fracture energies reported previous$1 \mathrm{y}$, have less physical meaning. That is to say, it is necessary to know the actual fracture surface area after (and also during) the fracture test. The purpose of this study is to measure the actual fracture surface area of the fiber reinforced ceramic matrix composite by the Kr-BET adsorption technique, and to evaluate the actual fracture energy of the composite.

\section{Experimental}

\subsection{Specimen}

The carbon fiber reinforced silicon nitride composite $^{20), 21)}$ was used as a specimen, which was supplied by Noritake Co., Ltd. for the activities of the committee (The Ceramic Society of Japan) for the standardization of testing methods for fracture energy. The composite was unidirectionally reinforced by carbon fibers (60\% in volume), and main crystalline phases of matrix were $\alpha-\mathrm{Si}_{3} \mathrm{~N}_{4}$ and $\mathrm{Si}_{2} \mathrm{~N}_{2} \mathrm{O} .{ }^{22)}$ The bulk density was $2.55 \mathrm{~g} / \mathrm{cm}^{3}$, and the open porosity was about $3 \% .{ }^{22)}$ The specimens were cut down in a rectangular shape (4 mm width $* 3$ $\mathrm{mm}$ thickness $* 40 \mathrm{~mm}$ lenght), and a chevron-notch (vertical angle $=120$ degree) as shown in Fig. 1, was introduced into the specimen.

2.2 Measurement of a surface area by the $\mathrm{Kr}$ BET adsorption technique

Brunauer, Emmett, and Teller ${ }^{23)}$ made up the adsorption theory of a multilayer of molecules, by expanding Langmuir's adsorption theory ${ }^{24)}$ of a monolayer. According to their theory, a total volume of adsorbing gas at an equilibrium pressure $P$ is expressed as follows,

$$
\frac{P}{V\left(P_{0}-P\right)}=\frac{1}{V_{\mathrm{m}} C}+\frac{C-1}{V_{\mathrm{m}} C}\left(\frac{P}{P_{0}}\right)
$$

where $P_{0}$ is a saturation pressure of adsorbing gas, $V_{\mathrm{m}}$ is a volume of a monolayer, and $C$ is a constant depending on the heat of adsorption. Therefore, a plot of data for $P / V\left(P_{0}-P\right)$ versus $P / P_{0}$ gives a straight line (BET plot), and a volume of a monolayer $V_{\mathrm{m}}$ can be calculated from the intercept $1 / V_{\mathrm{m}} C$ and the

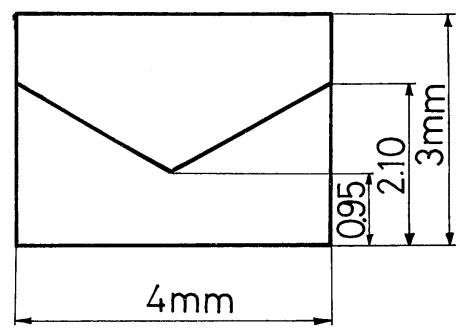

Fig. 1. The configuration of the chevron-notch of the specimen. 
slope $(C-1) / V_{\mathrm{m}} C$ of the line. The value of $V_{\mathrm{m}}$ converts to a total surface area of the specimen using the area occupied by one molecule.

In this study, the total surface area of a chevronnotched specimen was measured before and after the three-point-bending test. The measurement was conducted with the ORR surface-area pore-volume analyzer (Micromeritics: 2100A) at a temperature of $77.23 \mathrm{~K}$. $\mathrm{Kr}$ gas was used as a adsorbing gas, and the reduction of a pressure resulting from adsorption was measured repeatedly for one specimen, by changing the value of $P / P_{0}$ from 0.05 to 0.3 where the Eq. (1) can be used. The calculation was conducted using a saturation pressure, 2.42 Torr and the area occupied by one molecule, $0.208 \mathrm{~nm}^{2}$. The increase of a total surface area after the three-point bending test is defined as the actual fracture surface area in this study.

\subsection{Three-point-bending test}

The chevron-notched specimen was loaded into a three-point-bending fixture with a span length of 30 $\mathrm{mm}$ at a crosshead speed $0.1 \mathrm{~mm} / \mathrm{min}$. The average actual fracture energy $\langle\gamma\rangle$ is expressed as follows,

$$
\langle\gamma\rangle=\frac{\Delta W}{\Delta A}
$$

where $\Delta W$ is the work done during the whole fracture process, and $\Delta A$ is the change in the total surface area of the specimen after the bending test. The number of the specimens is two.

Furthermore, The chevron-notched specimen was loaded, and then unloaded (loading/unloading technique ${ }^{12)}$ ). This cycle was repeated until the specimen fractured completely. The actual fracture energy $\gamma$ is expressed as follows,

$$
\gamma=\frac{\mathrm{d} W}{\mathrm{~d} A}
$$

where $\mathrm{d} W$ is the work done during one cycle of loading and unloading, and $\mathrm{d} A$ is the change in the total surface area of the specimen after one cycle. The number of the specimen is two.

\section{Results and discussions}

3.1 Reproducibility and accuracy of surface area

The surface area was measured twice with one specimen to investigate reproducibility and accuracy of the measurement. Figure 2 shows the BET plots of these two data. Closed circles are the data of the first measurement, and open circles are those of the second measurement. The linear relationships in BET plots indicate that the Eq. (1) exactly consists with the data. Reproducibility of the measurement is also held in the experiments. Analyzing two data, the total surface areas in the first and second measurements are $0.214 \mathrm{~m}^{2}$ and $0.213 \mathrm{~m}^{2}$, respectively. Therefore, it is suggested that accuracy of the measurement is appropriate to this study.

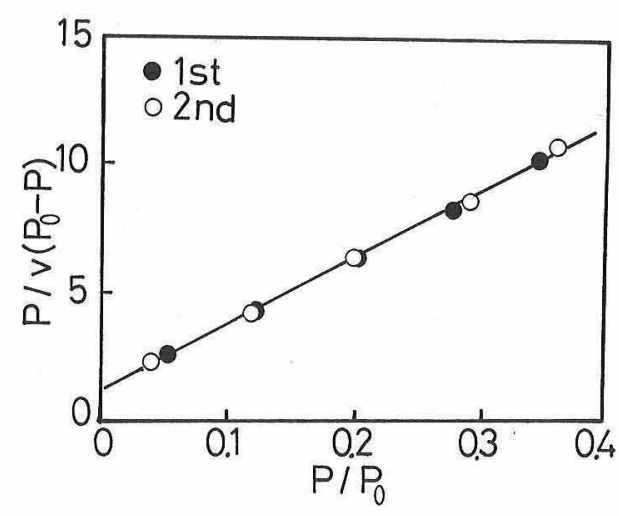

Fig. 2. The BET plots of data measuring one specimen twice. Closed circles are the data of the first measurement, and open circles are those of the second measurement.

\subsection{The average actual fracture energy of the composite}

The typical load/deflection curve of the composite is shown in Fig. 3. It is shown that the specimen has fractured after the manner of typical fiber reinforced composites. In the middle of the failure, the pullout of fibers was observed at a notch-ligament. The final pullout-length of fibers is $1-2 \mathrm{~mm}$, as shown in Fig. 4.

The work calculated from an area under the load/ defletion curve was about $0.25 \mathrm{~J}$, and the change in the total surface area after the three-point-bending test was about $0.016 \mathrm{~m}^{2}$. Using an area of the notchligament $\left(5.9 * 10^{-6} \mathrm{~m}^{2}\right)$ as the nominal fracture surface area, the apparent fracture energy of the composite is about $42 \mathrm{~kJ} / \mathrm{m}^{2}$. This value is nearly the same as the fracture energies of this specimens reported

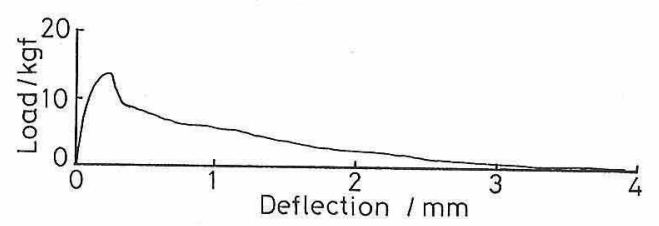

Fig. 3. The load/deflection curve of the carbon fiber reinforced silicon nitride composite.

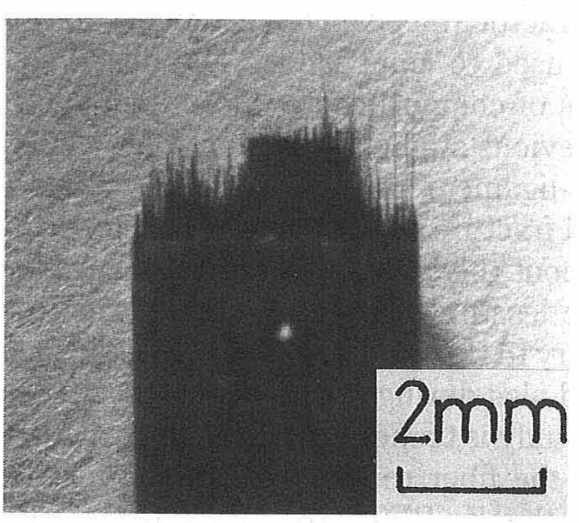

Fig. 4. The pullout of fibers after the bending test. 
previously. ${ }^{20), 21)}$

On the other hand, applying the Eq. (2), the average actual fracture energy $\langle\gamma\rangle$ of the composite, is about $16 \mathrm{~J} / \mathrm{m}^{2}$. This value is nearly the same as the fracture energies of polycrystalline ceramics reported previously. 1)-16) Therefore, it is considered that fiber reinforced ceramic matrix composites almost have microscopically the same fracture processes as polycrystalline ceramics. These results also suggest that the large energy-absorbing capacity of composites, depends on how the fracture surface area can increase until the specimen fractures completely.

3.3 The change in the actual fracture energy during the fracture process

The typical load/deflection curve of the composite is shown in Fig. 5. The change in the total surface area (normalized by an initial surface area) is plotted in Fig. 6. It is shown that the total surface area rapidly increases at an initial stage of the failure, and saturates to the constant value at a final stage of the failure.

Next, the actual fracture energy against the deflection at the maximum load was plotted as shown in Fig. 7. From this figure, it is shown that the actual fracture energy of the composite rapidly increases at an initial stage of the failure, and reaches at the same level of the fracture energies of polycrystalline ceramics (several $10 \mathrm{~J} / \mathrm{m}^{2}$ ). This result suggests that the cracks extends actually in the notch-ligament at an initial stage, and the actual fracture energy mainly depends on the formation of the fracture surface. Whereas, the actual fracture energy slightly reduces at a final stage of the failure, and gives the value of

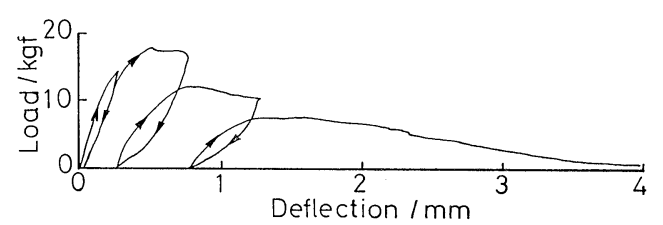

Fig. 5. The load/deflection curve of the specimen using a loading/unloading technique.

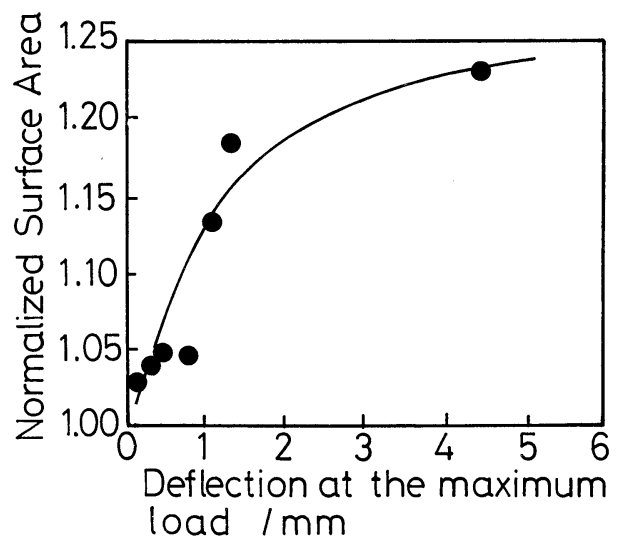

Fig. 6. The change in the normalized surface area during a bending test.

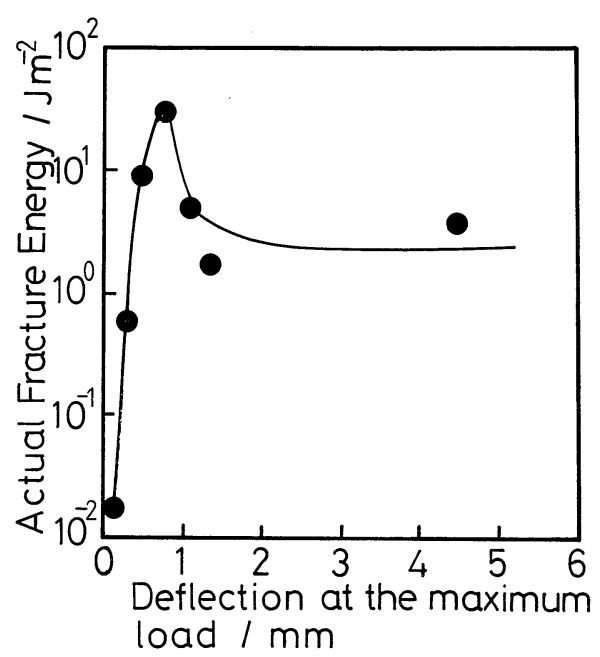

Fig. 7. The change in the actual fracture energy of the composite during the bending test.

several $\mathrm{J} / \mathrm{m}^{2}$. This means that the main energy-absorbing mechanism changes from the formation of the fracture surface to the pullout of fibers.

As mentioned above, applying the Kr-BET adsorption technique to the fracture of composites, we can get the quantitative information about the energy-absorbing mechanism of fiber reinforced ceramic matrix composites.

\section{Conclusions}

The fracture surface area of the chevron-notched carbon fiber reinforced silicon nitride composite, was measured by the Kr-BET adsorption technique. The energy-absorbing mechanism of the composite was discussed on the basis of the actual fracture energy. The average actual fracture energy of the composite is nearly the same as the fracture energies of polycrystalline ceramics. It suggests that the large energy-absorbing capacity of the composite depends on how the fracture surface area can increase. Furthermore, applying the loading/unloading technique to the composite, the actual fracture energy of the composite increases to a maximum at an initial stage of the failure, and then decreases to a constant value at a final stage. This indicates that the energy-absorbing mechanism changes from the formation of the fracture surface to the pullout of fibers.

Acknowledgement The authors thank the members of the committe (The Ceramic Society of Japan) for the standardization of testing methods for fracture energy, for their helpful discussions. We also express our gratitude to Prof. M. Daimon of Tokyo Institute of Technology for his kind help of the BET adsorption measurement, and to Noritake Co., Ltd., for supplying the specimens.

A part of this study was supported by the Japan Ministry of Education under a Grant-in-Aid for Scientific Research (No. 03750573). Another part of this study was the actibities of the committee (The Ceramic Society of Japan) for the standardization of testing methods for fracture energy. 


\section{References}

1) J. Nakayama, Jpn. J. Appl. Phys., 3, 422-23 (1964).

2) F. J. P. Clarke, H. G. Tattersall and G. Tappin, Proc. Brit. Ceram. Soc., 6, 163-172 (1966).

3) S. M. Wiederhorn, A. M. Shorb and R. L. Moses, J. Appl. Phys., 39, 1569-72 (1968).

4) P. L. Gutshall and G. E. Gross, J. Am. Ceram. Soc., 51, 602 (1968).

5) R. W. Davidge and G. Tappin, J. Mater. Sci., 3, 165-73 (1968).

6) S. M. Wiederhorn, J. Am. Ceram. Soc., 52, 99-105 (1969).

7) J. A. Coppola and R. C. Bradt, J. Am. Ceram. Soc., 55, 45560 (1972).

8) L. A. Simpson, J. Am. Ceram. Soc., 56, 610-11 (1973).

9) J. A. Coppola, D. P. H. Hasselman and R. C. Bradt, Am. Ceram. Soc. Bull., 52, 578 (1973).

10) L. A. Simpson, J. Am. Ceram. Soc., 56, 7-11 (1973).

11) L. A. Simpson, J. Am. Ceram. Soc., 57, 151-54 (1974).

12) M. Sakai, K. Urashima and M. Inagaki, J. Am. Ceram. Soc., 66, 868-74 (1983).

13) M. Inagaki, K. Urashima, S. Toyomasu and M. Sakai, Yogyo-Kyokai-Shi, 94, 186-87 (1986).
14) T. B. Troczynski and P. S. Nicholson, J. Am. Ceram. Soc., 70, 78-85 (1987).

15) M. Sakai, J. Yoshimura, Y. Goto and M. Inagaki, J. Am. Ceram. Soc., 71, 609-16 (1988).

16) P. Ostojic and R. McPherson, J. Am. Ceram. Soc., 71, 89199 (1988).

17) D. C. Phillips, J. Mater. Sci., 7, 1175-91 (1972).

18) C. O. Hulse, "Fracture Mechanics of Ceramics", Vol. 4, Ed. by R. C. Bradt, D. P. H. Hasselman and F. F. Lange, Plenum Press, N. Y. (1978) pp. 903-12.

19) M. Jenkins, J. Mikami, T. Chang and A. Okura, Trans. Jap. Insti. Meta., 29, 573-79 (1988).

20) M. Iwata, J. Jpn. Soc. Powder and Powder Metallur., 37, 1108-12 (1990).

21) T. Akatsu et al., "Proc. 1st Intern. Sympo. Sci. Eng. Ceram., Ed. by S. Kimura and K. Niihara, The Ceramic Society of Japan (1991) pp. 473-78.

22) Data of the committee for the standardization of testing methods for fracture energy (1990).

23) S. Brunauer, P. H. Emmett and E. Teller, J. Am. Chem. Soc., 60, 309-19 (1938).

24) I. Langmuir, J. Am. Chem. Soc., 40, 1361-403 (1918). 